\title{
Hypercarcinogenic State in Chronic Liver Disease
} Key words: hepatocellular carcinoma, cholangiocell carci-
noma

Major primary liver cancers are classified into hepatocellular carcinoma (HCC) and cholangiocell carcinoma (CCC). Most of primary liver cancer is HCC. It is well known that HCC develops in patients with cirrhosis, indicating a relationship between chronic liver disease and HCC. However, the mechanism of developing HCC (hepatocarcinogenesis) is still unclear.

Early studies have reported that the integration of hepatitis $B$ virus (HBV) into host chromosomal DNA plays a major role in HBV-related hepatocarcinogenesis (1-4). Other studies have indicated that proteins produced by part of HBV DNA (such as HBx protein) have roles in enhancing cell proliferation or inversely inducing apoptosis $(5,6)$. In any case, little is known about the mechanism by which HBV induces hepatocarcinogenesis.

It has recently become clear that many patients with HCC who are negative for $\mathrm{HBs}$ antigen are positive for $\mathrm{HCV}$ antibody, with a significant difference from control values. $\mathrm{HCV}$ causes chronic hepatitis that follows acute infection in most patients. In the long term, cirrhosis develops in patients with chronic hepatitis and, according to studies in Japanese patients, HCC develops after an average interval of about 30 years from acute infection (7). Thus, HCV infection is also considered in relation to hepatocarcinogenesis. Since $\mathrm{HCV}$ is a ribonucleic acid (RNA) virus that is not reverse transcribed to DNA, its association with oncogenesis cannot be explained by the integration of genomic material into the host chromosome. The virus may simply cause cirrhosis, in which it is a premalignant state with increased DNA synthesis. Other studies have suggested that $\mathrm{HCV}$ core protein enhances cell proliferation via the MAP kinase signaling pathway $(8,9)$. It is not as clear as with $\mathrm{HBV}$ whether or not $\mathrm{HCV}$ plays a direct role in hepatocarcinogenesis. Nevertheless, based on the number of patients with $\mathrm{HCV}$ infection who develop HCC, HCV seems to have a more important role in $\mathrm{HCC}$ than $\mathrm{HBV}$, at least in some countries including Japan.

The molecular mechanism of hepatocarcinogenesis may, however, not be explained solely by the roles of these hepatitis viruses. It is noteworthy that the most important process in hepatocarcinogenesis is genomic instability caused by chronic hepatitis (continuous inflammation) $(10,11)$. Since, in many cases, HCC develops through a long-term hepatitic state, regardless of infection with HBV or HCV. During a chronic inflammatory state, hepatocytes are repeatedly destroyed and regenerated. This process causes damage to genomic DNA and genomic instability, at the same time enhancing cell proliferation. Under these circumstances, hepatocytes must be initiated to the carcinogenic state by various mechanisms.

This situation is defined as "hypercarcinogenic state", the state in which genes are prone to mutation. Mutations are likely to accumulate in the tissue of chronic viral hepatitis $(12,13)$. In this state, normal cells have a tendency to initiate carcinogenesis and an initial cell is promoted to a cancer cell.

Interestingly, there is a tendency to generate not only $\mathrm{HCC}$ but also CCC in chronic liver disease induced by HBV infection $(14,15)$.

See also $\mathrm{p} 624$.

It suggests that hepatitis per se is associated with hepatocarcinogenesis rather than the hepatitis virus (HBV) directly inducing hepatocarcinogenesis, if hepatitis virus does not infect the cholangiocytes. Furthermore, statistically, there are many patients with $\mathrm{CCC}$ who are positive for $\mathrm{HCV}$ antibody in Japan (30.4\%) (16). Taken together, we suppose that developing CCC also is more closely associated with chronic inflammation rather than with an identical role of the two different hepatitis viruses. Thus, the "hypercarcinogenic state" induced by chronic viral hepatitis may not only influence hepatocytes but also cholangiocytes and other cell as well. Further investigation is necessary to clarify the molecular mechanism for the hypercarcinogenic state in chronic liver disease.

Tomoyuki UMEDA, MD, PhD and Okio HiNo, MD, PhD
The Department of Experimental Pathology, Cancer Institute,
1-37-1 Kami-Ikebukuro, Toshima-ku, Tokyo 170-8455

\section{Reference}

1) Edman JC, Gray P, Valenzuela P, Rall LB, Rutter WJ. Integration of hepatitis $B$ virus sequences and their expression in a human hepatoma cell. Nature 286: 535-538, 1980.

2) Hino $\mathrm{O}$, Kitagawa $\mathrm{T}$, Koike $\mathrm{K}$, et al. Detection of hepatitis B virus DNA in hepatocellular carcinomas in Japan. Hepatology 4: 90-95, 1984.

3) Hino O, Kitagawa T, Sugano H. Relationship between serum and histochemical markers for hepatitis B virus and rate of viral integration in hepatocellular carcinomas in Japan. Int J Cancer 35: 5-10, 1985.

4) Hino $O$, Shows TB, Rogler CE. Hepatitis B virus integration site in hepatocellular carcinoma at chromosome 17;18 translocation. Proc Natl Acad Sci USA 83: 8338-8342, 1986.

5) Koike K, Moriya K, Yotsuyanagi H, Iino S, Kurokawa K. Induction of cell cycle progression by hepatitis $\mathrm{B}$ virus $\mathrm{HBx}$ gene expression in quiescent mouse fibroblasts. J Clin Invest 94: 44-49, 1994.

6) Shintani Y, Yotsuyanagi H, Moriya K, et al. Induction of apoptosis after switch-on of the hepatitis $\mathrm{B}$ virus $\mathrm{X}$ gene mediated by the Cre/loxP re- 
combination system. J Gen Virol 80: 3257-3265, 1999.

7) Kiyosawa K, Sodeyama T, Tanaka E, et al. Interrelationship of blood transfusion, non-A, non-B hepatitis and hepatocellular carcinoma: analysis by detection of antibody to hepatitis C virus. Hepatology 12: 671-675, 1990.

8) Aoki H, Hayashi J, Moriyama M, Arakawa Y, Hino O. Hepatitis C virus core protein interacts with 14-3-3 protein and activates the kinase Raf-1. J Virol 74: 1736-1741, 2000.

9) Hayashi J, Aoki H, Kajino K, Moriyama M, Arakawa Y, Hino O. Hepatitis $\mathrm{C}$ virus core protein activates the MAPK/ERK cascade synergistically with tumor promoter TPA, but not with epidermal growth factor or transforming growth factor alpha. Hepatology 32: 958-961, 2000.

10) Hino $O$, Tabata $S$, Hotta $Y$. Evidence for increased in vitro recombination with insertion of human hepatitis B virus DNA. Proc Natl Acad Sci USA 88: 9248-9252, 1991.

11) Kajino K, Hotta $Y$, Hino O. Determination of a putative recombinogenic human hepatitis $\mathrm{B}$ virus sequence and its binding cellular protein. Cancer
Res 54: 3971-3973, 1994.

12) Hino O. Mechanisms of viral carcinogenesis: From hyper carcinogenic to normo- or hypocarcinogenic states. Intervirology 38: 125-126, 1995.

13) Umeda T, Hino O. Molecular aspects of human hepatocarcinogenesis mediated by inflammation: from hypercarcinogenic state to normo- or hypocarcinogenic state. Oncology 2001 (in press).

14) Shiozawa $K$, Ishii $K$, Mori $T$, et al. Heterochronous development of intrahepatic cholangiocellular carcinoma following hepatocellular carcinoma in a hepatitis B virus carrier. Intern Med 40: 624-630, 2001.

15) Takegoshi K, Su Q, Omata M, et al. Cholangiocarcinoma with a background of hepatitis B virus-associated cirrhosis. Intern Med 40: 382-385, 2001.

16) Liver cancer study group of Japan. Survey and follow-up study of primary liver cancer in Japan: report 13. Kanzoh (Acta Hepatol Jap) 40: 288-300, 1999 (in Japanese, Abstract in English). 